Article

\title{
Potential Pathways to the German Bioeconomy: A Media Discourse Analysis of Public Perceptions
}

\author{
Sophia Dieken *(i) and Sandra Venghaus (1) \\ Institute of Energy and Climate Research: Systems Analysis and Technology Evaluation (IEK-STE), \\ Forschungszentrum Jülich, Wilhelm-Johnen-Straße, 52428 Jülich, Germany; s.venghaus@fz-juelich.de \\ * Correspondence: s.dieken@fz-juelich.de; Tel.: +49-2461-61-5204
}

Received: 31 August 2020; Accepted: 21 September 2020; Published: 27 September 2020

\begin{abstract}
The bioeconomy has emerged as a popular, but ambiguous vision for a sustainable future. Its implementation depends not only on novel products and production processes, but also on balancing diverse interests, values, and interpretations of the concept. The German government's plan to develop a sustainable bioeconomy in response to structural change in the lignite mining regions provides a unique opportunity to investigate what pathways towards the bioeconomy are supported by society. In order to characterize bioeconomy visions prevalent in public perception, we conducted a computer-assisted, mixed-methods discourse analysis of German-language newspaper articles published between 2010 and 2019. Results show that a techno-economic vision is dominant over ecological and social aspects, suggesting only one clear pathway to the German bioeconomy, which is increasingly criticized in the public debate.
\end{abstract}

Keywords: bioeconomy visions; bioeconomy discourse; sustainability transformation; Germany; public perceptions; media

\section{Introduction and Background on the German Bioeconomy}

A large number of current global challenges revolve around the use of fossil resources; from the supply security of finite resources to climate change and environmental degradation. The "bioeconomy" emerged as a concept in policy and research communities to address these challenges and provide an alternative, sustainable development model. Broadly speaking, the term encompasses transitioning from a fossil-based economy to the sustainable use of biomass and biotechnology. Though ambitious in the envisioned changes to economy and society, the bioeconomy concept is highly relevant in the pursuit of the global Sustainable Development Goals (SDGs) due to its direct link to the challenges related to the use of fossil resources.

However, the concept's broad definition and diverse policy strategies complicate the assessment of how the bioeconomy could contribute to sustainable development. Following a landmark 2007 expert conference by the European Union (EU) [1] and an influential 2009 report by the Organisation for Economic Co-operation and Development (OECD) [2], multiple countries, especially in Europe, devised national bioeconomy strategies. These range from a strong focus on woody biomass and the forest industry in Scandinavian countries to support programs for life sciences and biotechnology, e.g., in Austria [3]. The variety in bioeconomy approaches does not only depend on national resource availability and capacities for research and development (R\&D), but also on underlying interests, values, and visions of the societal actors involved [4] (p. 19), [5] (p. 5). Throughout strategic documents, the acceptance and participation of society are identified as key to successfully implementing the bioeconomy (e.g., [6]). Thus, next to techno-economic feasibility assessments, researching the bioeconomy also requires analyzing how the concept is understood and perceived. 
The current understanding of the bioeconomy, however, is highly problematic. Arguably, the core problem is that, often, the bioeconomy concept is unknown to the broader public and the affected stakeholders [7] (p. 46). However, even if the concept is known, understandings can differ widely between its official definition in policy documents and the positions of stakeholders [8,9]. This ambiguity risks the concept of being appropriated by vested interests, calling into question societal acceptance even more [10]. Specifically, environmental concerns may only serve a rhetorical purpose in the understanding of the bioeconomy [11] (pp. 48-51). Thus, a systematic and detailed analysis of societal perspectives on the bioeconomy is needed.

Germany provides an interesting case for analyzing bioeconomy perceptions. The country is characterized by both large industrial and research clusters on the one hand and regionally strong agricultural sectors on the other, including the traditionally influential farmers' and forest owners' associations-thus, having good starting conditions for a national bioeconomy [6]. Like several of its EU neighbors, Germany published its first bioeconomy strategy shortly after the OECD report, in the form of a national research strategy. The "Nationale Forschungsstrategie BioÖkonomie 2030" (National Research Strategy BioEconomy 2030) [12] identifies priorities for research funding in science and engineering against the background of global challenges like hunger and nutrition as well as the national dependence on fossil fuels in industrial and energetic uses. The research strategy and a subsequent policy strategy from 2014 [13] were updated to a comprehensive national strategy in 2020. The "Nationale Bioökonomiestrategie" (National Bioeconomy Strategy) [6] explicitly understands the bioeconomy as an economic model in line with the SDGs and devises two strategic elements: research and real-world application of biological knowledge and the sustainable production and circular use of biomass. To include society in the transformation process is formulated as an explicit objective of the strategy. Arguably, this reinforced focus is also a result of the experiences with another grand sustainability project, the German Energiewende (energy transition), which encompasses the phase-out of lignite mining and power production [14], and has been repeatedly faced with obstacles to implementation in the form of local citizens' initiatives (e.g., [15]). In 2019, a government-installed expert commission drew a direct link between both sustainability transformations, suggesting the development of a bioeconomy in the lignite-mining regions affected by structural change [16]. The commission was installed against the background of both the country's climate mitigation goals and the impending end to economically viable lignite mining in the country. This tense and complex context of the bioeconomy transformation in Germany further highlights the necessity to closely investigate society's perspectives on what future, and what pathway towards it, are conceivable. Even though the German government has extended its public outreach format for bioeconomy research to a second year [17], the question of what society's perspective is on how the bioeconomy can and should be designed and implemented in Germany remains largely unanswered.

Therefore, this paper aims at characterizing bioeconomy visions prevalent in the German public perception in order to identify potential pathways for a bioeconomy transformation. To this objective, a computer-assisted, mixed-method discourse analysis of German-language newspaper articles was conducted for the time period between 2010 and 2019. Building on Bugge et al.'s categorization of three different bioeconomy visions—bio-technology, bio-resource, and bio-ecology [18] —we develop a framework for identifying bioeconomy visions in media texts. Analyzing quantitatively which visions appear in the articles and how their use has shifted over time, we detail qualitatively what understanding these visions entail. Delineating synergies and conflicts between bioeconomy visions allows us to identify potential pathways for a bioeconomy transformation in Germany. We conclude the article by summarizing the results and identifying promising avenues for further research.

\section{Conceptual and Methodological Framework}

In order to analyze German public perceptions of the bioeconomy, we developed a conceptual framework based on discourse theory and analysis (Section 2.1). The methodological approach rests on 
the computer-assisted coding of text segments from German-language news media articles, allowing for a mixed-method analysis (Section 2.2).

\subsection{Bioeconomy Discourses}

As alluded to in the introduction, science and policy increasingly recognize the sociopolitical dimension of a bioeconomy, acknowledging that the policy and social frameworks are key drivers of bioeconomy development [19] (p. 239). Thus, the bioeconomy can also be understood as a process of political and social change [9] (p. 17) [10] (pp. 3-4).

Birch follows a similar line of thinking in conceptualizing the bioeconomy as, on the one hand an imaginary, and on the other a set of policies and institutional changes, specifically, a future-oriented framing of current policies for future opportunities [20] (p. 2). Thus, in this article, the bioeconomy will be understood as a vision for the future shaped not only by what is techno-economically feasible, but also by society's perceptions and expectations of the bioeconomy.

Discourse analysis is a social-constructivist approach commonly used for investigating policy choices, for example, in the field of environmental policy [21,22]. In this context, discourse is defined as "an ensemble of ideas, concepts, and categories through which meaning is given to social and physical phenomena, and which is produced and reproduced through an identifiable set of practices" [22] (p. 175), specifically, texts such as policy documents or newspaper articles. As such, analyzing discourses can also serve to reveal underlying political dynamics and worldviews [23] and explain how policy choices [22] (pp. 176-177) and institutional change come about [20] (pp. 2-4).

A central feature of discourse is that it is contested. Given its role in producing and reproducing reality, discourse reflects and shapes, e.g., the distribution of funds, and is thus constantly interpreted and reinterpreted by actors according to their interests and values. Societal and political actors may refer to commonly used concepts and ideas, but actors can attribute different meanings to them or attempt to change their understanding [22] (p. 177). Thus, identifying the specific underlying visions is crucial to analyzing discourse and, thus, public perception.

Current works on bioeconomy discourses often consider a limited set of actors or a specific aspect of the overall understanding of the bioeconomy. Thus, Peltomaa suggests analyzing media texts as a reflection of the broader public discourse [10]. Drawing on literature on news media's impact on public perception, Ranacher et al. suggest thinking of media texts in terms of two processes: media filters the communication of visions to the public and simultaneously provides a stimulus to the public to form their own visions [24]. Thus, investigating media texts is especially relevant for identifying what visions public discourse entails, and which of those are most prominent [25]. Thus, in this article, we conduct a media discourse analysis of bioeconomy visions in Germany in order to characterize the public perception of the bioeconomy and potential pathways towards a transformation.

A growing amount of research is dedicated to conceptualizing the bioeconomy and analyzing perceptions prevalent with stakeholders and within society in general. Many works highlight the ambiguity of the bioeconomy concept and how this leaves room for different, potentially conflicting interpretations (e.g., $[9,10,26])$. Therefore, generally, two or more visions of the bioeconomy are found that differ, sometimes considerably, in their theoretical underpinnings and their design and implementation suggestions.

A key characteristic of bioeconomy visions discussed in scientific literature is the relation to sustainability. Giurca, for example, considers the bioeconomy's sustainability as a conflicting storyline that has three interpretations: "Bioeconomy as a risk to sustainability", "Sustainability as a standard" (i.e., sustainability requires setting standards for the bioeconomy), and "Sustainability as inherent to bio-based products" [26] (pp. 5-6). Because sustainability is defined according to assumptions about how humans can use and substitute natural capital [27], the understanding of the bioeconomy's sustainability is linked to the underlying assumptions about scarcity [28] (pp. 10-11) [29] and growth (e.g., $[11,28])$. In sum, these conceptual contributions suggest two opposing visions; the "economization of ecology" and the "ecologization of the economy" [28] (p. 10). 
The dichotomy between an economically-driven and an ecologically-driven vision is reflected in several empirical works. For example, both Stern et al. (2018) and Priefer et al. (2019) find that bioeconomy perceptions can be generally divided into a technology-focused vision and a socioecological vision $[4,30]$ that align with the "economization" and "ecologization" visions, respectively. However, these conceptualizations of the bioeconomy are relatively abstract.

Bugge et al. offer a conceptualization of three visions, which connects these basic assumptions to their implications for the objectives and design of the bioeconomy. The "bio-technology" vision focuses on bio-technology research and commercialization across sectors, the objective of economic growth, and a global scale of competition [18] (pp. 10-11). The "bio-resource" vision focuses on upgrading and converting biological raw materials, primarily in agriculture, marine, forestry, and bioenergy. In both cases, the objectives are economic growth and sustainability, and further concerns include the cascading use of biomass and land use, emphasizing research and innovation more broadly as well as development in rural areas [18] (pp. 11-12). The "bio-ecology" vision focuses on the optimization of energy and nutrient use, the promotion of biodiversity, and the avoidance of soil degradation, preferably on a regional level. Primary objective is sustainability, emphasizing circular and self-sustained production modes as well as organic bio-ecological practices, preferably at a local level [18] (pp. 12-13). The authors point out that these visions are not distinct, but interrelated [18] (p. 9). This categorization allows for distinguishing the broad bioeconomy concept between different pathways highlighting research and development, biomass production, or the optimization of local practices, respectively. For example, Peltomaa (2018) and Hausknost et al. (2017) apply this framework to the empirical analysis of bioeconomy visions $[9,10]$, with the second one explicitly pointing out that Bugge et al.'s vision can be mapped to the economization-ecologization dichotomy as well [9] (p. 5).

For the German case specifically, only few works investigate the bioeconomy discourse. Kiresiewa et al. (2019) conduct an extended literature review and find that research has either focused on individual sectors and aspects or investigated European or international discourses [7]. Investigating texts by government and stakeholders, they find that the German bioeconomy discourse is predominantly affirmative, highlighting innovation and competitiveness and understanding the bioeconomy as a technological fix [7] (pp. 74-80). Research on the portrayal of the German bioeconomy in media, in particular, is lacking, with the notable exceptions of Puttkammer and Grethe (2015) and Ranacher et al. (2019) [24,25]. Kiresiewa et al. (2019) identify that one reason for this is a lack of in-depth discussion in the German media, which is generally tied to specific occasions [7] (pp. 113-114). Additionally, German media discourse, concerning biofuels specifically, is found to be dominated by political and economic actors holding a supportive stance [25]. These works demonstrate that analyzing German media discourses on the bioeconomy is a relevant, but challenging, endeavor.

Thus, in this article, we aim to identify several specific policy visions of the bioeconomy, which encompass understandings of its general characteristics, suggested pathways for its implementation, and policy objectives as rationale for its realization.

\subsection{Methodological Approach}

Our methodological process consisted of three steps. First, we determined the data set (Section 2.2.1). Second, we developed a categorization of visions (Section 2.2.2) based on the literature reviewed in Section 2.1, and third, we derived a coding scheme (Section 2.2.3). By conducting a media discourse analysis, we are able to consider the broader societal discourse on the bioeconomy instead of specific actor groups or sectors. However, media texts as data basis provide several limitations to discourse analysis on the basis of coding, which we will discuss in the following where it applies.

On a general note, news media articles vary considerably in length, writing style, and purpose, which makes it difficult to conduct a comparative quantitative analysis on the level of text that is meaningful. Thus, we decided to conduct a mixed-method approach on the level of the document. First, we coded the texts according to our coding scheme introduced in Section 2.2.4. Second, we conducted a quantitative analysis of the number of articles referencing certain visions across time, regardless of 
how often the visions were referenced within an article. Because, according to this approach, articles can refer to more than one vision, the total numbers of articles referencing the visions in the following sections will add up to more than the total number of articles. Third, we conducted a qualitative analysis of coded segments in the context of the broader text, allowing us to substantiate the results from the second analytical step with an in-depth look beyond the document level.

\subsubsection{Data Selection}

A central challenge in analyzing media discourses on the bioeconomy is the selection of data. The identification of all news media articles related to the bioeconomy is a pointless undertaking. Because the concept is so variedly and widely defined, an enormous amount of activities, objectives, and measures can be attributed to it-from genome editing to self-sufficient living. Arguably, all reporting on, e.g., agriculture, the chemical industry, energy supply, nutrition, and sustainability could be categorized as bioeconomy-related articles, making for a convoluted amount of texts to analyze. Thus, we limited the analysis to texts that explicitly refer to the bioeconomy concept, thus identifying issues as bioeconomy-related for the researcher-and notably, the reader. We searched the databank lexisnexis for news media articles referencing the term bioeconomy and variations of it (German: "Bioökonomi*"; * indicates that the term is incomplete, allowing for the German language's particularity of compound words to be accounted for in word searches). This approach also helps to prevent a normative bias in selecting documents by the researcher, who naturally have their own understanding of the bioeconomy.

Moreover, because we focus on German public perceptions, we limited the results to German-language articles. Additionally, we chose a timeframe to limit results to a relevant period in time and to a reasonable amount of data. The year 2010 was chosen as the starting point because, in that year, the first German bioeconomy strategy was published. The year 2019 was chosen as the endpoint because it coincided with the publication of the latest national strategy in January 2020, and was the point in time this analysis was conducted.

Selecting the documents forming the data basis proved to be difficult due also to a unique characteristic of news media texts: Often, articles—especially ones by local newspapers-will be highly derivative of national press releases. This means that several texts published by different outlets and at different dates will be identical or only differ in a few words or sentences. This causes two problems for a systematic analysis: First, the amount of duplicates can distort the actual substance of the debate by being biased towards news releases that are published in a large amount of newspapers, regardless of their geographical reach. Second, and closely related, the tendency of local newspapers to copy or insignificantly change articles by central press organizations makes it difficult to distinguish between local and national reporting in a document analysis, which requires an unequivocal definition of document variables. Thus, we decided to exclude the duplicates, and not conduct a representative study of media texts in the given timeframe, and instead conducted an in-depth mixed-method analysis of discourse trends in the overall public debate.

Excluding duplicates followed two general rules: (1) if texts are identical, eliminate all but the earliest one, and (2) if texts differ in terms of small edits, eliminate all but the most extensive one. Next to that, a first screening of the documents revealed that several articles do not include the term bioeconomy in the text, but only in a byline or an attachment-these texts were excluded as well. Additionally, four articles were excluded due to being inaccessible to the authors. As a result, we selected a database of 784 media articles.

Figure 1 displays the number of German-language media articles that include the bioeconomy term and its derivatives for the period between 2010 and 2019. Because these numbers exclude duplicates as defined above, the graph does not show a representative depiction of all bioeconomy-related publications. Instead, the increase in standalone articles on the topic is shown. The development is relatively stable across the investigated timeframe, but with a notable peak in 2019. Arguably, the presence of the bioeconomy concept in the German public perception has steadily increased. From this initial description of data, we draw the question of whether the increase in reporting also reflects on the content of the debate. 


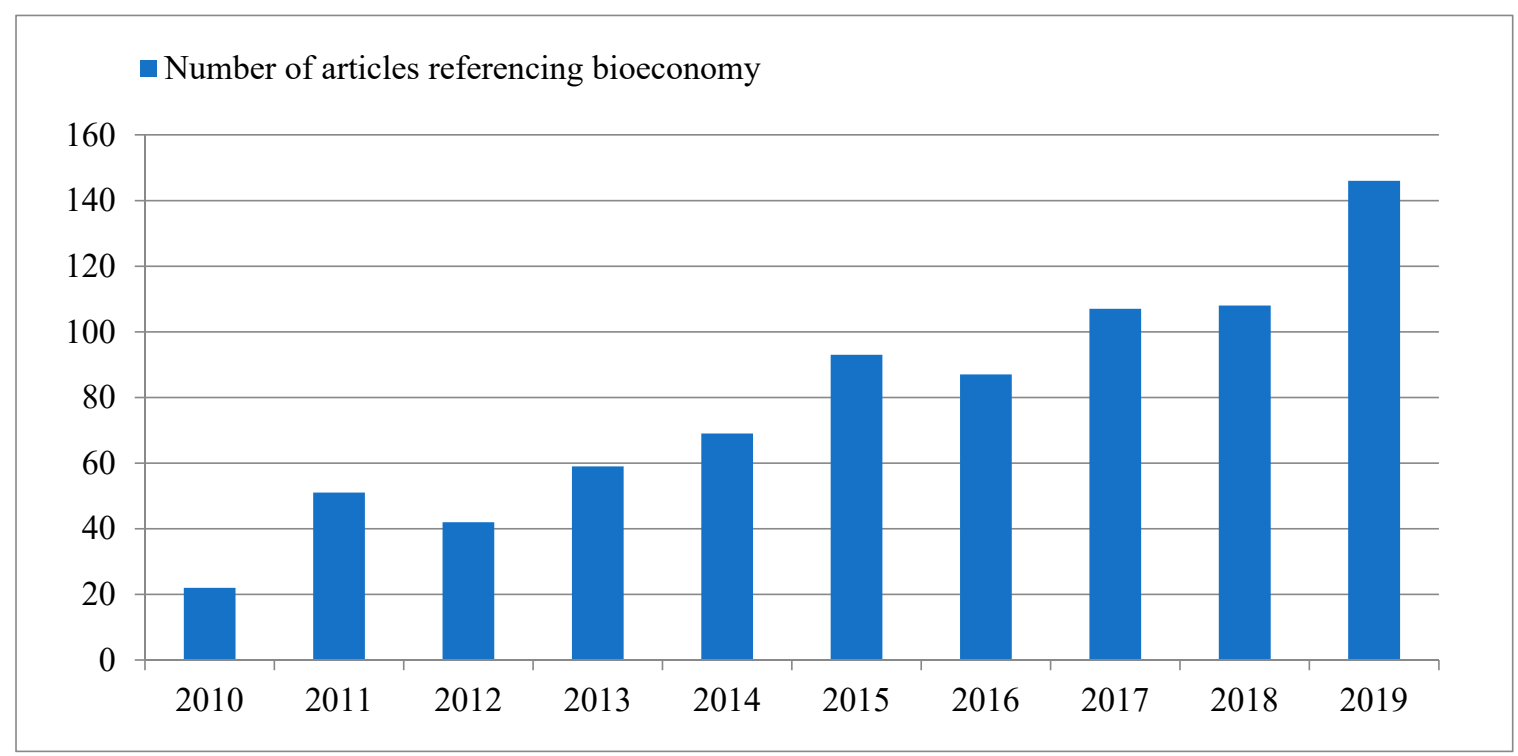

Figure 1. Number of articles referring to the term bioeconomy, 2010-2019.

\subsubsection{Data Analysis}

Within the scope of the data, i.e., not being representative but indicative of trends (as indicated in the section above), we conducted search inquiries into the frequency of key words in order to establish the context for analyzing visions and make first observations about themes present in the public perception. To this end, we first identified words associated with the bioeconomy concept by compiling a word cloud via the data analysis program MAXQDA (2018) [31], showing the words occurring most often in the articles of our data set (filler words were excluded from the results using a stop-list). Then, we identified key terms for conducting a word search based on the word cloud (see Tables A1 and A2 in Appendix A). Search inquiries were conducted via MAXQDA, and results were calculated by the authors. The results show the share of articles referring to the respective key terms in a given year, with 0 meaning no articles and 1 meaning all articles included the term. The results of both steps are summarized in Section 3.

\subsubsection{Analysis of Bioeconomy Visions}

Given our intention to differentiate between several potential pathways towards the bioeconomy, we follow Birch (2016) in understanding bioeconomy visions as uniquely identifiable but closely interrelated sets of assumptions about a preferred future socioeconomic model and the means to achieve it [20]. We aim to characterize which elements are predominantly focused on, or come under the umbrella of, the bioeconomy discourse in order to identify gaps and conflicts in the development and implementation of the bioeconomy, consequently pointing out potential transformation pathways.

For the bioeconomy visions, we chose to apply Bugge et al.'s 2016 framework of differentiation between "bio-technology", "bio-resource", and "bio-ecology" [18]. This approach allows us to include two lines of thinking from research. On the one hand, these three visions build on the fundamental assumptions about nature and sustainability identified in conceptual literature. On the other hand, these visions are specific enough to allow for statements about the real-life design and implementation of the bioeconomy. They are thus a suitable framework for analyzing the visions held by the public; this was supported by an initial screening of the media articles and previous applications of Bugge et al.'s visions [9,10]. Based on Bugge et al., and informed by the literature reviewed in Section 2.1, we defined each vision according to a set of four unique characteristics, which serve as the basis for coding the media articles (see Table 1). 
Table 1. Characteristics of bioeconomy visions (based primarily on Bugge et al., 2016).

\begin{tabular}{|c|c|}
\hline Bioeconomy Visions & Key Characteristics \\
\hline Bio-technology vision & $\begin{array}{l}\text { - } \quad \text { research and development of biotechnology and } \\
\text { bio-based products } \\
\text { - } \quad \text { new or refined products and processes, often drop-in solutions } \\
\text { - } \quad \text { concerns about commercialization and global competition } \\
\text { - } \quad \text { objective of economic growth }\end{array}$ \\
\hline Bio-resource vision & $\begin{array}{l}\text { - } \quad \text { upgrading and converting of biomass (primarily in } \\
\text { biomass-producing sectors and bioenergy) } \\
\text { - } \quad \text { cascading use of biomass } \\
\text { - } \quad \text { concerns about land use and rural development } \\
\text { - dual objective of economic growth and sustainability }\end{array}$ \\
\hline Bio-ecology vision & $\begin{array}{l}\text { - optimized ecological processes (especially regarding energy } \\
\text { and nutrients) } \\
\text { - circular and self-sustained modes of production and organic } \\
\text { - } \quad \text { practices, preferably local } \\
\text { - } \quad \text { objective of sustainability }\end{array}$ \\
\hline
\end{tabular}

\subsubsection{Coding Scheme and Coding Process}

The media discourse was analyzed with an established procedure of content analysis, text-based development, and attribution of codes to applicable text segments [32,33]. Coding was conducted via MAXQDA. We applied a mixed-method approach, analyzing the codes both quantitatively and qualitatively.

The coding scheme consists of the three codes "bio-technology", "bio-resource", and "bio-ecology" (see Table 2). Text segments were assigned one of these codes if they referred to one or several of the characteristics defined in Section 2.2.2. In order to identify the bioeconomy as a comprehensive vision, we coded not only the sentence the term appears in, but the whole document. Exception to this are articles that are clearly divided into distinct sections (e.g., lists of event summaries), in which case we coded only the relevant section. In total, 2356 codes were assigned to the 784 texts. The results of coding are presented in Section 3.

Table 2. Coding scheme.

\begin{tabular}{cc}
\hline Coding Category & \multicolumn{1}{c}{ Codes } \\
\hline \multirow{3}{*}{ Bioeconomy visions } & Bio-technology vision \\
\cline { 2 - 2 } & Bio-resource vision \\
\cline { 2 - 2 } & Bio-ecology vision \\
\hline
\end{tabular}

Originally, coding was intended to entail respective sub-codes for the characteristics of the three bioeconomy visions. However, the level of depth on which the bioeconomy is considered in the texts differs strongly. Short news articles would define the bioeconomy in a sub-clause or list of sample products, while a few essays discuss specific ideas and policy options behind the concept. This distorts the application of detailed sub-codes, because they could only be assigned to a handful of texts that were not necessarily representative of the overall discussion at that point in time. Thus, we decided to focus on the identification of fewer and broader visions, which enabled us to assign both more general ideas and specific policy options to a clearly defined set of understandings of the bioeconomy. This is in line with the understanding of bioeconomy as a comprehensive vision for the future, as discussed above. 


\section{Results of the Discourse Analysis}

In this section, we present the results of the discourse analysis on the presence of each vision, and how visions are linked to each other in the media texts. We begin by presenting some initial findings on the key terms used, which form the context of the specific bioeconomy visions.

As explained in the preceding section, we focus exclusively on texts that self-identify as related to the bioeconomy concept. Although all these texts explicitly use the term at least once, they differ in terms of the definitions, themes, and issues described. Most notably, bioeconomy is rarely explicitly defined. If an explanation is given, it is often limited to describing the bioeconomy as a bio-based alternative economic model characterized by R\&D efforts and new high-tech methods and products (e.g., [34,35]).

Overall, the bioeconomy concept is rarely the sole focus of an article, but is often the frame of reference for zooming in on a certain aspect. Consequently, articles can focus on such diverse issues as the competitiveness of novel bio-based value-chains, community land-use planning, or global hunger. Generally, media articles on the bioeconomy are published on relevant occasions, i.e., they deal with a specific policy, product, or research project. Thus, these articles present a specific point of focus of the bioeconomy understanding. While the absence of bioeconomy definitions can be explained in part by news articles being generally short, it supports the concern about a lack of understanding among the public.

In the articles, the bioeconomy concept is used in the context of specific key terms. A word cloud depiction of the most-frequently used terms (Figure A1) reveals a clear dominance of a technical and economic framing. Next to the bioeconomy term itself, the three most-frequently used terms are Germany, BRAIN, and biotechnology. BRAIN AG is a German company from the field of industrial biotechnology. This heavy leaning towards biotechnology issues is further highlighted by the common use of terms such as company, industry, research, and science. Nevertheless, the words included in the cloud also range across many different fields, e.g., energy, agriculture, nutrition, raw materials, politics, or sustainability. Next to the predominantly national focus, there are also many references to regional hubs of bioeconomy research and development, such as the Forschungszentrum Jülich and the universities of Hohenheim, Stuttgart, and Bonn. While this might also be explained as a result of news being tied to specific events and projects, the diverse locations referenced show that the bioeconomy in German public discourse is linked to its regional manifestations.

This initial picture of the bioeconomy in the media is further supported by the search results for the frequency of key terms (Figure A2). A notable change has occurred in the references to biotechnology and biomass. While the terms were initially used often, being included in almost two out of three articles in 2012, references dropped to $20 \%$ and $10 \%$, respectively, in 2019 . This suggests that the bioeconomy understanding has moved away from the core definition of using biomass and biotechnology, or has at least broadened to include other aspects.

Both references to bioeconomy products and bio-based resources and raw materials form a significant part of the German public bioeconomy understanding. Since 2010, the number of articles on the bioeconomy referencing these aspects has fluctuated by around $50 \%$. However, since the references to other aspects dropped after 2012, products and resources have become the aspects most frequently referred to in the articles. There is arguably a close connection between these two aspects and the terms biotechnology and biomass. Therefore, instead of losing importance, issues surrounding biomass and biotechnology seem to have been reframed more recently in debates about bio-based products, resources, and raw materials. In addition, this hints at a strong industrial focus of the German bioeconomy understanding.

References to energy and food within the bioeconomy debate have developed similarly for the most part of the 2010s, dropping from almost half of all articles in 2013 to roughly $40 \%$ in 2018. Before, however, energy had been mentioned in the most articles compared to all other terms, then dropped sharply. For 2019, a slight upwards trend was found, but energy has lost its dominant position in the German debate. This may also be a result of the discourse shift towards the general use of resources 
and raw materials, rather than isolated considerations of specifically-and controversially-bioenergy. The development of references to food and nutrition is almost reversed. In the early 2000s, food was mentioned in few articles before the numbers recovered, but in 2019, references dropped again to below $40 \%$ of all articles. While the development does not suggest that either aspect, energy or food, will become the dominant issue of the German bioeconomy debate, both hold a significant share and are even more present than biotechnology or biomass. Instead, this suggests that the demand-side of the bioeconomy constitutes a major element of the German public debate, which must be considered in the further analysis.

Lastly, we looked at circularity, a prominent characteristic of research and policy debates on the bioeconomy, but notably absent from our word cloud. Indeed, we found this term to appear in the least amount of articles compared to the other terms we investigated. Following no mentions in 2010, references have slowly increased, transcending the $10 \%$ mark only in 2019 . This is particularly interesting because - of the terms we investigated—only circularity incorporates a systemic perspective on the bioeconomy. Thus, the question must be raised as to whether the understanding of the bioeconomy is holistic or sectorally fragmented. The results of the word searches provide a frame of reference for the analysis of bioeconomy visions.

\subsection{Prevalent Visions}

In this section, we analyze visions of the bioeconomy prevalent in the media articles. We first summarize how the use of these visions has developed between 2010 and 2019, before detailing each vision individually.

Figure 2 shows to what degree the bio-technology, bio-resource, and bio-ecology visions were used in the media in the investigated time period. The most important result of this comparison is the big and continuous difference between the visions. The vision most often used is the bio-technology vision, which is referred to in more than $80 \%$ of all articles during almost the whole decade, but has slowly been decreasing in its presence. Nevertheless, the bio-technology vision is by far the predominant interpretation of the bioeconomy in the media. This supports the word search findings that the bioeconomy debate is characterized by techno-economic terms, in terms of science and industry. In general, German public understanding of the bioeconomy centers on a bio-technology vision.

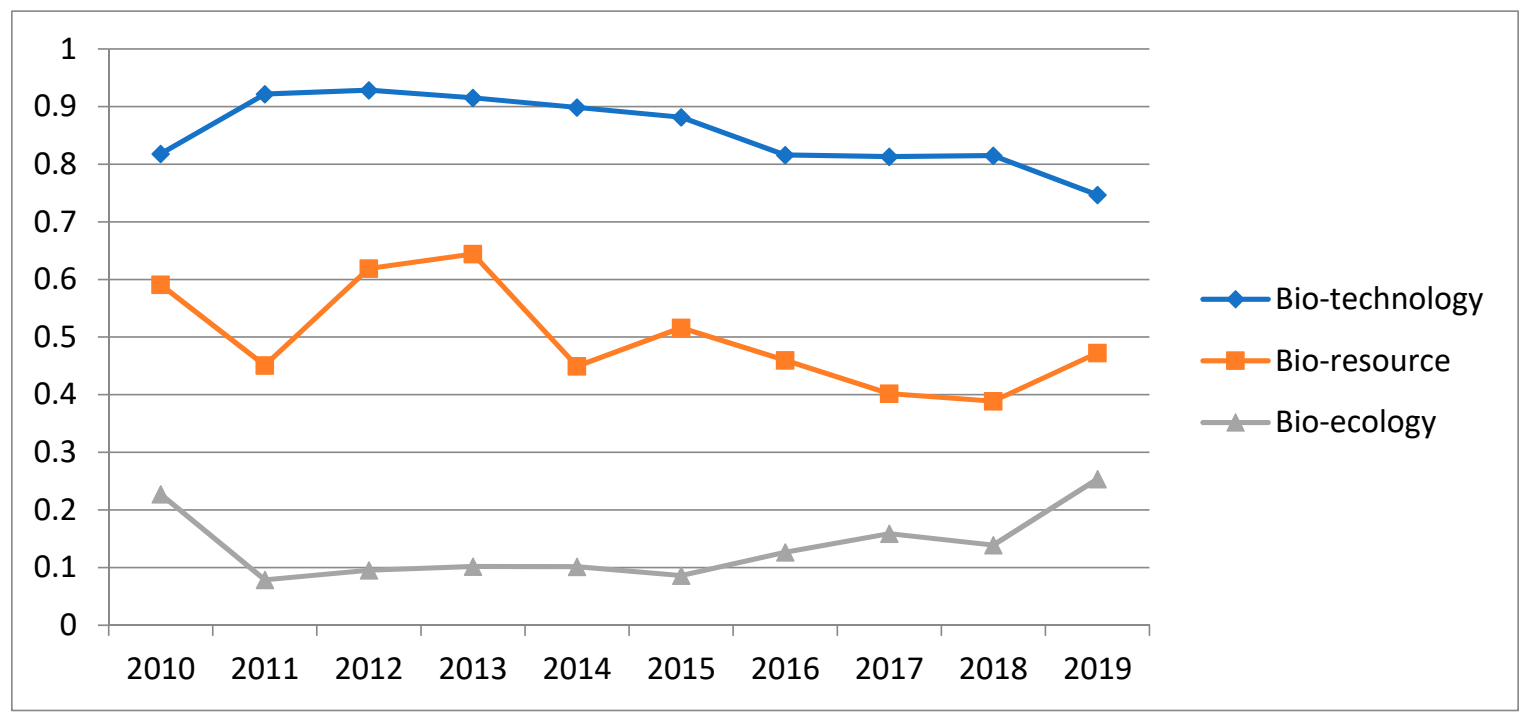

Figure 2. Visions prevalent in bioeconomy media articles, 2010-2019 (depicted as share of articles referencing each vision).

The bio-resource vision is referred to in roughly half of all articles, although the use of this vision is less consistent. To begin with, the vision was used more often in the first half of the 2010s than in the 
second half. References decreased from $64 \%$ in 2013 to approximately $40 \%$ of all articles, although the share has risen again to almost half of the texts in 2019-but it would be too early to interpret this recent uptake as a larger trend because the results of the word searches indicate that the debate has diversified in general in 2019. It is also noteworthy that the short-lived increase in references in 2012 and 2013 correlates with uptakes in the use of the terms biomass and resources and raw materials (see Figure A2). Thus, bio-resource is the second most often used bioeconomy vision in German media texts. While references to it differ substantially from the use of the bio-technology vision and fluctuate over time, overall, the bio-resource vision is still highly present. The analysis of visions shows that the drop in usage of the terms biotechnology and biomass is not related to the comparatively stable development of the usage of the respective visions. Instead, it seems that the visions are referenced increasingly in regard to other characteristics and elements than simply the primary terms associated with them.

The bio-ecology vision is referred to in the least amount of articles. The vision was initially referred to in approximately every fifth text in 2010, but the share dropped to less than $10 \%$ after and has only slowly recovered since 2016. In comparison to the frequent references to sustainability issues, this low presence is surprising and raises questions on how the vision is understood specifically in the German context. Overall, media articles are dominated by the bio-technology vision, and the bio-resource vision is also a common point of reference. In contrast, the bio-ecology vision is only used in few articles.

Next, we detail how the bioeconomy visions are understood and used in the specific context of German news media articles. Here, we supplement the conceptual literature and the quantitative results with our qualitative findings.

\subsubsection{The Bio-Technology Vision}

As the word searches already indicate, the bio-technology vision and its focus on science and technology dominate in the German media discourse on the bioeconomy. The core of this vision is to understand the bioeconomy as research and development of biotechnology and bio-based products. In line with this perspective, the bioeconomy is primarily defined in economic terms, such as by a list of sectors [36], or a list of professions that economize biological resources (German: "wirtschaften mit biologischen Ressourcen") [37]. Expert journals assess the bioeconomy according to the economic output of selected sectors (e.g., [38]).

Specifically, this understanding of the bioeconomy rests on innovation for an alternative economy. In the media articles, bioeconomy is often interpreted as solving technological and scientific problems [39]. Alternatively, the term is explicitly defined as a cooperation between science and industry [37] or scientists and engineers [40]. In this context, articles heavily reference EU and German research policy (e.g., [36,37,41,42]), which shows that the German bioeconomy vision is deeply embedded in the EU conceptualization of a knowledge-based (bio)economy. Two main perspectives can be distinguished in terms of bioeconomy as research and development. One prominent perspective understands the bioeconomy primarily as optimizing plant breeding and farming, thus putting a heavy focus on plant sciences [43]. This perspective is thematically connected to the bio-resource and bio-ecology visions, but focuses instead on research. The second main perspective features the application of biotechnology in industry, especially the chemical industry, and aims to optimize processes and identify new products and technologies [41]. Thus, the bio-technology vision in the German media focuses on research on the production and utilization of biomass and, thus, on the techno-economic conditions of supply.

Against this background, the bioeconomy is envisioned as a new and innovative model of the economy. To implement it, a structural change of industry is required ("Strukturwandel von einer erdöl- zu einer biobasierten Industrie") (e.g., $[35,39,44])$. This includes switching the resource base from fossil to biological resources [42,45], also termed a transformation in the raw materials base ("Rohstoffwandel") [46]. This short form presentation is met with skepticism. For example, 
the bioeconomy is mockingly defined as simply the modernization of agriculture [36], or criticized for the fact that using biomass in products is not new [40]. Here, the bio-technology vision loosely connects to the bio-resource vision by defining the bioeconomy via its resource base, but it sets the focus on biomass utilization in research and industrial production.

Consequently, biotechnology is a key element of the bioeconomy understanding in the media. Trade journals identify industrial biotechnology as a core technology of the transformation towards the bioeconomy (e.g., [41]), and more general reporting describes biotechnology as a priority of the German bioeconomy strategy [36]. A further indicator of the key role of biotechnology in media discourse is the significant presence of the German biotech company BRAIN AG in articles [34,41,47]. Moreover, numerous trade journals from the chemical industry report on biotechnological innovations (e.g., [42,48]).

Biotechnology is further presented as unique in contrast to conventional technologies, due to the assumed special relation to nature. First of all, the bioeconomy is conceived of being at the intersection of biology and technology, constituting a biological transformation [41,49] or rather a biologization of industry ("Biologisierung der Industrie") (e.g., [34,41]). In this context, nature is understood as a design template and toolbox ("Werkzeugkasten des Lebens") [34,41]. This means that biological processes are used technologically in industry [41]. Thus, the bioeconomy is presented not only as an innovative economic model, but also as one that differs in substance because it is based on biological processes.

The second key feature of the bio-technology vision is the focus on new or refined products and processes. The bioeconomy is most often defined by technical innovations, such as new products or technologies (e.g., [34-36,39,40,42,44,45,47,49]). Other articles that report, e.g., on policy developments and economic trends, often give a list of bio-based alternatives to everyday products [34,44]. For example, a local newspaper article from 2019 describes a futuristic vision of everyday life in the bioeconomy based on high-tech and on-demand production, linking aspects such as growing food at home and three-dimensional-printing individualized medicine [49]. Popular, often-cited examples of bio-based everyday products are cleaning agents produced with bio-technology $[34,39,44]$ or ice cream based on lupins [44]. Articles refer to both products that substitute for fossil-based products and ones that are completely new. On the one hand, articles point out that fossil-based base chemicals can be produced on the basis of biomass or by means of biotechnology as well, offering the perfect substitution $[44,48]$. On the other hand, articles investigate which bio-based base chemicals could be promising for developing new products [42] and highlight the idea that bio-based products are superior to fossil-based products [44]. Bio-refineries are a less straightforward element of the German bio-technology vision. Either they are discussed purely in terms of processes' techno-economic potential (e.g., [45]) or they are referenced in the context of biomass upgrading [44]. Thus, bio-refineries are included in both bio-technology and bio-resource visions and can serve as a link (see also Section 3.2).

Given the predominant interpretation of the bioeconomy as a techno-economic phenomenon, in the bio-technology vision, concerns mostly revolve around commercialization and global competition. Descriptions of biotechnology are usually accompanied by highlighting hurdles to the market introduction of new products, especially because business perspectives feature prominently in the texts. Concerns about commercialization include the need to establish new value chains [36] and start-ups [39]. Additionally, articles highlight the challenges of adapting processes to the different input and the diverging quality of biomass [40]. Objectives are gaining profit and market shares in new and growing segments such as enzymes and food [40,41,48]. In terms of global competition, articles argue either in terms of international competitiveness [50] or the pressures on bio-based products stemming from the low international oil price [34,42]. These aspects further underline the primarily economic perspective on the bioeconomy.

Accordingly, in this vision, the primary objective of the bioeconomy is economic growth. Innovation, produced within the bioeconomy, is argued to drive the growth of the national economy, and, thus, employment and market shares. Here, articles reference national policy, especially the government advisory board Bioökonomierat $[34,36]$. All in all, this vision is focused on techno-economic 
challenges and opportunities on either the company or the global level, assigning science and industry the key driving roles.

Contrary to our expectations derived from the literature, we found an abundance of references to the sustainability objective within the context of the bio-technology vision. It is repeatedly stated that the bioeconomy is only possible in combination with sustainability (e.g., "es gibt keine Bioökonomie ohne Nachhaltigkeit") [51]. Word search results for sustainability show that the term (and its derivatives) is overall used 1137 times in 378 of the 784 documents. However, the connection is drawn only superficially, stating a natural link between sustainability and economic objectives within the bioeconomy. Articles on BRAIN AG embody this argument by stating that, by using biological resources to improve products and processes, they can provide more energy efficient, more resource saving, and more sustainable production processes [41]. This argument of the use of biological resources or the application of biotechnology enabling resource efficiency and, thus, sustainability is the fundament of most iterations of the bio-technology vision. Thus, the analysis of visions supported the observation of the sustainability term's high presence in the articles but found little substance behind the frequency of its use.

We found it particularly interesting that the bio-technology vision is the only one explicitly identified and criticized as a guideline for the bioeconomy. For example, by environmental activists claiming that German policy is attempting to solve problems technologically, even though these problems were caused by technological progress to begin with ("Der Bioökonomierat setze die "lange Tradition" fort, "mit Ingenieurskunst und technischem Fortschritt all die Probleme lösen zu wollen, die aus technischem Fortschritt und einem verengten Verständnis von Natur und Umwelt resultieren".") [37]. The article even explicitly refers to the economization of ecology by questioning the common assumption that ecological farming and biotechnology were not conflicting concepts [37]. The continuing references to ecological objectives in German policy are instead criticized for trying to appease all claims while still focusing heavily on the development of biotechnology [37]. Thus, the co-occurrence of the bio-technology vision and sustainability concerns cannot be automatically assumed to constitute a broadening of the rather one-sided techno-economic focus, but instead it is rather the result of a rhetorical connection for legitimization reasons, or to the contrary, constitutes explicit criticism of the bio-technology vision. More interestingly, there is an awareness of the predominant bioeconomy understanding being only one potential interpretation. The bio-technology vision is even used consciously as hyperbole to criticize the current policy direction, e.g., when one article concludes that the bioeconomy is simply about wrapping technologies into products to improve the industry's competitiveness [51]. In sum, while the media discourse on the bioeconomy is predominantly characterized by the bio-technology vision, there is also a distinct awareness of this fact and a number of voices critical of its underlying assumptions.

\subsubsection{The Bio-Resource Vision}

The bio-resource vision was identified as the second most frequently used vision in the German media articles. As the in-depth analysis of the dominant bio-technology vision showed, the bio-resource vision has many ties to it. By focusing on the use of biomass, this vision is often referenced when supporting the call for a switch of industry's resource base.

In this vision, the bioeconomy is first and foremost understood as a biomass-based economy. Expert journals, for example, estimate the bioeconomy according to economic activities based on the use of biomass; a literal biomass-economy (e.g., [35,38]). In other articles, the bioeconomy is specified as entailing sustainable agriculture and the subsequent use of biomass for industry, energy, and food (e.g., [35,43]), emphasizing the shift in the resource base [39,43,51]. However, different from the bio-technology vision, which focuses primarily on the utilization process, here the bioeconomy is seen from the perspective of biomass production. Several articles discuss the bioeconomy in the context of agriculture (e.g., [37,43]) or present farmers as key drivers of the transformation (e.g., [51]). In an article by the national newspaper Die Zeit, agricultural production is presented as the starting 
point of the bioeconomy, from where biomass moves up to the bio-refinery and to industry, energy, and food [37]. In a slightly different interpretation, articles also deal with resources provided by the chemical industry. Here, different resource generations and material flows, and their utilization options, are discussed. Utilizing such materials in the bioeconomy provides more resource efficiency and preservation [46]. Since both interpretations also reference research, the bio-resource vision is often used alongside the bio-technology vision.

One characteristic that distinguishes the bio-resource vision from the bio-technology vision is the cascading use of biomass. Articles using the biomass vision focus on identifying utilization options for biomass, presenting, e.g., research projects on using woody biomass [39] or a range of product options for wood production waste [44]. In addition, this includes recycling municipal and industrial waste [46]. However, this focus is difficult to identify in the media because articles often refer to the term circular economy, evoking the bio-ecology vision's principle of circularity, but then detail how to upgrade waste streams instead of presenting a systemic approach to closing resource cycles (e.g., [47]). This paper's mixed-method approach enabled us to differentiate by an in-depth qualitative analysis and resulted in attributing most portrayals of circularity in the articles to the bio-resource vision and the discussion of cascading use.

The second defining element of the bio-resource vision consists in concerns about land-use and rural development. Given the primary focus on resources, this vision includes the spatial dimension of the bioeconomy explicitly, especially in terms of constraints on biomass availability. Resource efficiency and climate change (and its impacts) are identified as underlying challenges of the bioeconomy [46]. The bio-resource vision is often evoked when discussing the bioeconomy in terms of monocultures, land grabbing, deforestation, and competition with food [34], as well as in terms of the supply security of food and energy and biomass [51]. A general concern is poor soil, e.g., in the aftermath of lignite mining [43]. Climate change specifically is made out to be a major challenge to agriculture, which could be mitigated by transforming towards a bioeconomy.

Against this background, the bio-resource vision specifically acknowledges the potential for conflicts of use. In the bioeconomy, agriculture is required to satisfy multiple demands for biomass, potentially sparking conflicts about the limited resource [37]. This conflict plays out between food and industrial and energetic uses of biomass against the background of a growing population and rising consumption demands [51]. Thus, expert journal articles often highlight that industry is determined to use no resources eligible as food [44]. One article states that the chemical industry should focus on "previously unused resources" instead of "cannibalizing" food and feedstuff [45] (translated by authors). Thus, the bio-resource vision is more critical of the bioeconomy than the bio-technology vision, acknowledging the need to balance different objectives, such as demand-side challenges.

The spatial understanding of the bioeconomy is expressed in the suggestion of a regional bioeconomy. It is argued that cascading processes are best implemented on a regional scale [43]. Some articles thus deal with regional bioeconomy approaches, e.g., in the German lignite mining regions of the Lausitzer Revier [52] and the Rheinische Revier [53]. However, regional approaches are not limited to rural communities (e.g., the city of Frankfurt/Main) [46]. In general, media articles present a diverse range of regional bioeconomies as an alternative to the national-level approach suggested by the dominant bio-technology vision.

Next to discussions about challenges caused by the bioeconomy, the bioeconomy is also presented as a viable solution for mitigating regional structural change. In the regional context, the bioeconomy is supposed to be implemented as a sustainable and profitable alternative to the fossil-based economy, which is undergoing structural change in the three remaining German lignite mining regions [43]. For all EU regions in general, the bioeconomy's potential to generate jobs is projected [54]. Thus, the bio-resource vision is not simply critical of a bioeconomy pathway, but also optimistic about its influence on rural development as well as about the economic potential of utilizing waste streams.

The bio-resource vision's dual perspective on the availability challenges and development opportunities of the bioeconomy explains the presence of two general objectives: economic growth 
and sustainability. Compared to the bio-technology vision, the objectives within the bio-resource vision are less clear and one-directional. On the one hand, the vision includes the economic goals of competitiveness and profit as well as regional growth. For example, the economic opportunities of using waste materials and their contribution to competitiveness and employment is highlighted [47]. Moreover, the bioeconomy is presented as an opportunity for regional growth and local employment (e.g., [47]). On the other hand, the bioeconomy's contribution to social and ecological sustainability challenges is included. Texts express the need to manage climate change and environmental protection, energy and resource supply, and food security (e.g., [36]). Particularly in regards to environmental degradation caused by agriculture, the bioeconomy is required to address climate change (e.g., [34]). All in all, the bio-resource vision spans diverse objectives across the economic, environmental, and social dimensions of the bioeconomy, allowing for a broader and more differentiated perspective. Moreover, the analysis of visions reinforces the observation from the word searches that products and resources are the most frequently used key terms.

\subsubsection{The Bio-Ecology Vision}

Compared to the two other visions, the bio-ecology vision plays only a minor role in German media articles; nevertheless, it introduces a distinct perspective to the discourse. A key theme of this vision is the optimization of natural resources. Some texts or voices within articles underline the priority of safeguarding natural processes, e.g., as practiced in organic farming [51]. The bioeconomy is understood as the implementation of principles of nature [49], which is replicated in the cycle of materials [41]. Specifically, the focus rests on optimizing such processes, e.g., by changing the characteristics of plants [43]. By conceiving of the bioeconomy as cycles, this vision follows systems thinking regarding, not individual technologies and products, but a circular economy that uses raw materials and waste as often as possible [34]. However, neither the bio-ecology nor the bio-resource vision are used often, so circularity is not a central idea in the media articles, as was observed in the word searches.

Concerns about the state of resources are not presented with regard to supply security, as in the bio-resource vision, but instead in terms of their ecological repercussions. For example, when addressing soil degradation, the focus lies not on resource availability, but on ecosystem services, e.g., plants' ability to bind dust and to water soil in former mining areas that lie idle [43]. Thus, the bio-ecology vision entails a systemic perspective, including several dimensions of the bioeconomy, and prioritizes the environment.

Similar to the bio-resource vision, this more holistic perspective on the bioeconomy leads to a consideration of local developments and impacts. Some articles conceive of a local circular economy, arguing that a bottom-up approach is easier to implement [34,43]. The frequent inclusion of regional approaches in the bio-ecology and bio-resource visions underlines the findings of the word search (see Section 3).

This bottom-up approach to the bioeconomy entails the regional and sustainable production of healthy and affordable food [43]. Organic farming is referenced explicitly as a practice in this line of thinking, highlighting that productivity is not only understood as yield, but also as ecosystem services [51]. However, the objectives of food security and nutrition are primarily discussed in terms of taking responsibility for global development and sustainability, not as a national issue [36]. The bio-ecology vision attempts to bridge this gap by suggesting the importance of thinking globally by acting regionally [43]. This vision differs from the other two in that it has a holistic perspective, but it is also less specific about the design and implementation of the bioeconomy.

In this vision of the bioeconomy, the core objective is sustainability. In contrast to the other visions, the bio-ecology vision provides a more critical understanding of the relation between sustainability and the bioeconomy. This vision acknowledges that bio-based production is not automatically sustainable, but requires additional efforts [43]. Moreover, the bio-ecology vision is the only one that considers sustainability in terms of its social dimension, specifically questions of justice, equity, and participation. 
A few texts emphasize the idea that society is key in implementing the bioeconomy. For example, one article criticizes the single-minded focus on technology and resources as causes of hunger, and points to education, infrastructures, and income inequality as well. Moreover, it is highlighted that the implementation of the bioeconomy depends on societal acceptance [37]. Genetic engineering constitutes a major acceptance problem in the German public, but also other approaches, such as organic farming, are described as lacking the necessary societal support [51]. Moreover, the bioeconomy transformation also relies on behavioral changes, which cannot be expected to happen automatically [34]. Lastly, some articles argue that the implementation of technologies in society requires society to take part in this transformation, instead of limiting the debate about the bioeconomy to a select group of experts and scientists [49]. Even more technology-focused articles acknowledge this argument by noting that a network among stakeholders is necessary to garner acceptance and provide the capability to drive the bioeconomy transformation [41]. In the bio-ecology vision, socioeconomic aspects of the bioeconomy are explicitly called to attention [37]. Thus, both the bio-ecology and the bio-resource visions consider the demand-side as essential in the bioeconomy, in contrast to the bio-technology vision. However, social issues are limited to the rarely used bio-ecology vision.

In the articles, the role of society was mainly discussed as a challenge to the bioeconomy and not in terms of potential measures and pathways and, thus, connected easily to the predominant visions. Nevertheless, societal acceptance and participation have emerged as notable concerns in the media discourse, originating in the bio-ecology vision's acknowledgement of social sustainability. Due to this more critical understanding of the relation to sustainability, this vision is also more critical of the bioeconomy, identifying diverse challenges-although only in a few articles, as demonstrated above.

\subsection{Relations between Visions}

In this section, we analyze how the bioeconomy visions relate to each other. First, we summarize the co-occurrence of these visions, and then we detail, for each vision, how the respective arguments and ideas connect to each other.

Figure 3 shows the share of articles referring to more than one bioeconomy vision, depicted according to the respective link. Generally, there are more articles referring to one vision than articles referring to two or more. Only less than $10 \%$ of articles refer to the bio-technology and bio-ecology visions, or to the bio-resource and bio-ecology link, or to all three visions at the same time. Given the limited use of the bio-ecology vision in general, the link between bio-technology and bio-resource visions was the only one to be found frequently. Over the time period under investigation, at least $20 \%$ of all articles referred to both bio-technology and bio-resource at the same time. This share was found to be much higher during the first half of the decade, reaching almost $50 \%$ in 2013 , before declining in use. Thus, the two most present bioeconomy visions are frequently linked in media articles. The decrease in share can be explained by the overall decrease of references to the bio-technology and bio-resource visions (see Section 3.1). 


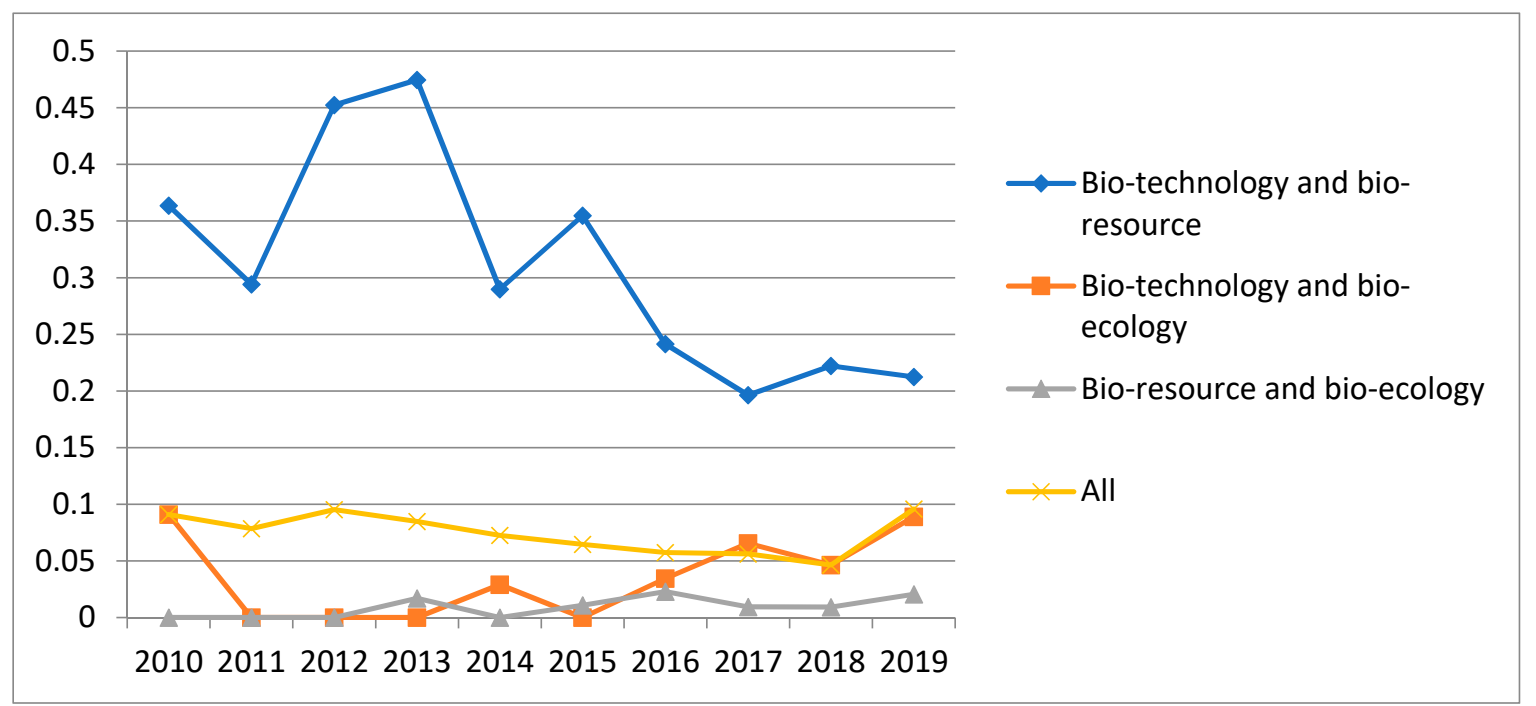

Figure 3. Co-occurrence of bioeconomy visions, 2010 and 2019 (depicted as share of all articles referencing two or more visions).

In terms of links made to the bio-ecology vision, Figure 3 highlights the fact that the use of both the bio-technology and bio-ecology visions has increased on a low level for the period since 2016. However, this increase is almost congruent with the increase of references to all three visions at the same time. Consequently, the marginal role of the bio-ecology vision is also visible in the few connections that are made to this vision.

Next, we compared the data for links between visions with the data we have for the individual visions. This provided us with further insight into how these visions are used. As Figure 4 indicates, the bio-technology vision is most often referenced separately, not in connection with other visions. This further supports our result that the bio-technology vision is the predominant understanding of the bioeconomy in the media. As mentioned above, this vision is also regularly used in connection with the bio-resource vision and occasionally also as part of a holistic presentation of the bioeconomy that references all visions, with an exclusive focus on the link between bio-technology and bio-ecology being the exception. Thus, the bio-technology vision is predominant in the media articles and used distinctively compared to the other visions.

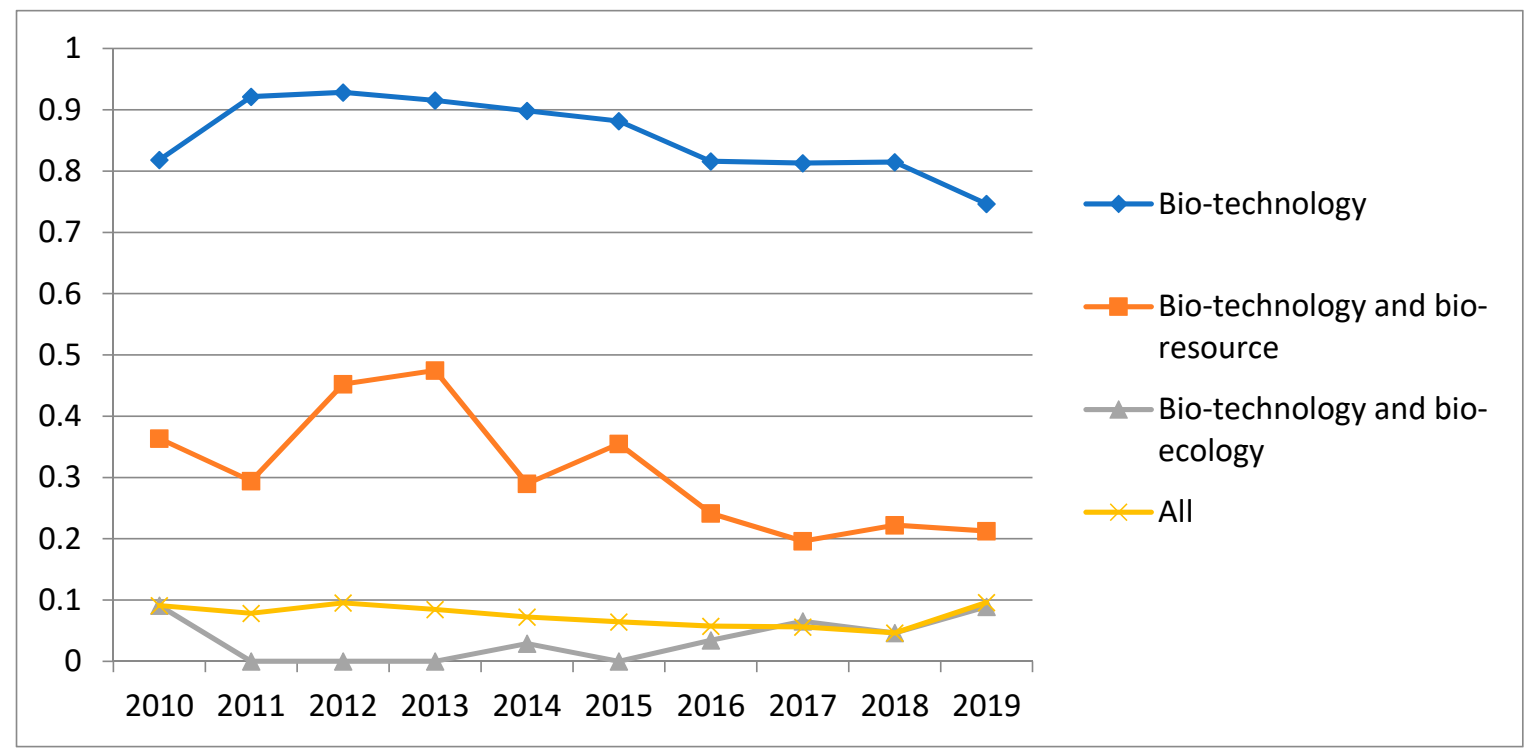

Figure 4. References to bio-technology in relation to other visions, 2010-2019 (depicted as share of all articles referencing two or more visions). 
In contrast, the bio-resource vision is primarily used in connection with the bio-technology vision, as depicted in Figure 5. This link forms a consistent part of the references to the bio-resource vision, and only for 2019, we found a divergence between an uptake in bio-resource references and a decrease in simultaneous references to both bio-technology and bio-resource visions. Due to the bio-resource vision's primary focus, it acknowledges challenges for the bioeconomy, which the bio-technology vision usually excludes due to the assumption of the bioeconomy's inherent sustainability. Nevertheless, the bio-resource vision does not stand in opposition to the bio-technology vision. Both visions complement each other, linking a bottom-up and a top-down perspective on the utilization of biomass. As mentioned in the preceding sections, bio-technology and bio-resource visions are argumentatively close. Many articles feature an integrated perspective on a bio-based value-chain, defining the bioeconomy as biomass production and biotechnical processing (e.g., [36]), blending both visions together. Similarly, the bioeconomy is defined as using natural resources in industrial production [41]. Mostly, these two visions interlink in the field of agricultural research and precision farming. For example, the national newspaper Die ZEIT featured a debate between two researchers about agricultural research policy, discussing the bioeconomy as a guiding principle [51]. In addition, articles argue for technical solutions by referencing global resource challenges, e.g., BRAIN AG describes the bioeconomy transformation as being driven by climate change, resource scarcity, and population growth, as well as by consumer choices and rising health costs [41]. The argument is built on two elements. First, the bio-resource vision is employed to characterize the state of resources and potential challenges. Second, these challenges are then linked to the bio-technology vision in order to argue for research and development in the pursuit of growth, with sustainability as a side-effect.

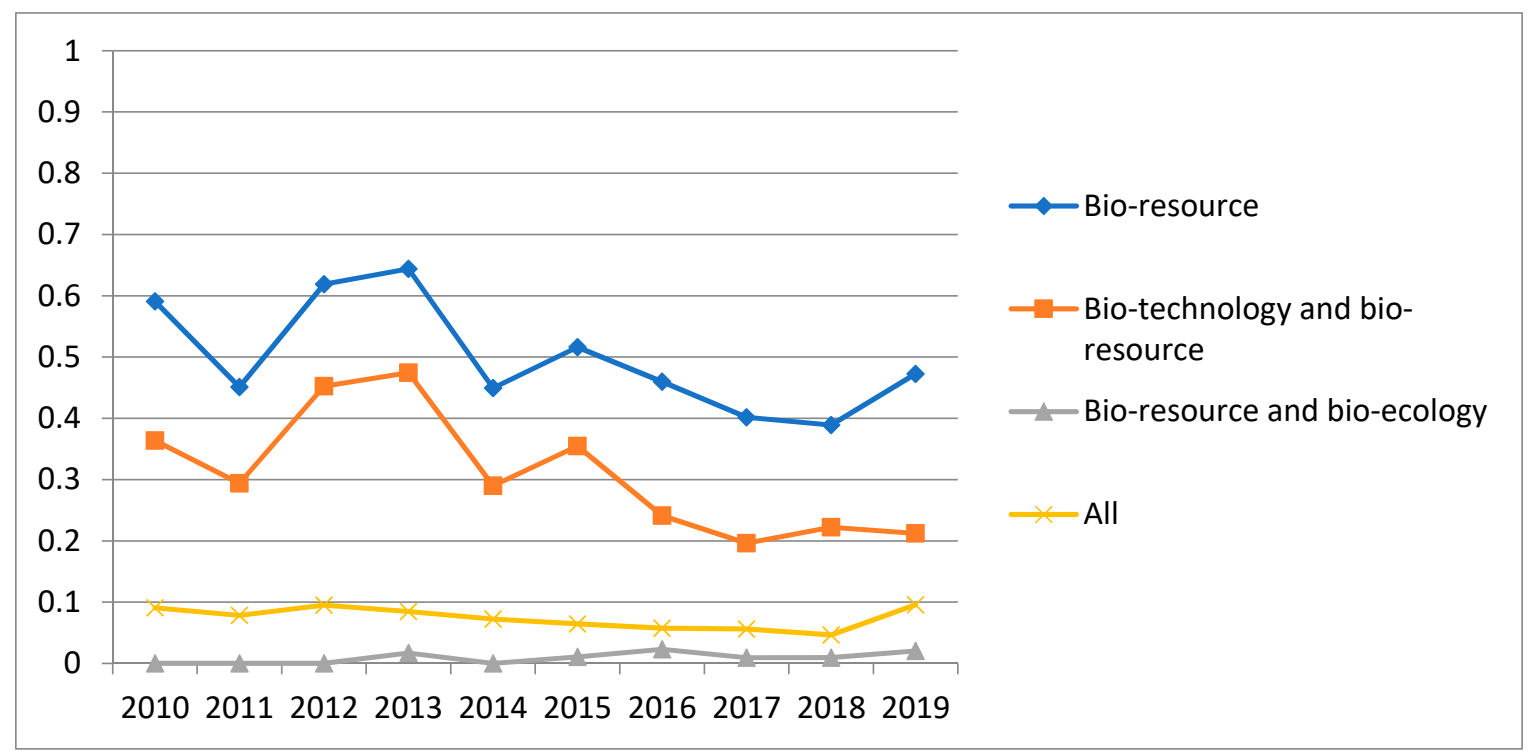

Figure 5. References to bio-resource vision in relation to the other visions, 2010-2019 (depicted as share of all articles referencing two or more visions).

As in the case of the bio-technology vision, links to the bio-ecology vision are a niche phenomenon and primarily consist of uses of all three visions at the same time. Bio-resource and bio-ecology visions mostly intersect in terms of development policy [51] and, again, agricultural practices [34]. However, this can be better explained by thematic proximity, i.e., concerns about ecological impacts, than by an argumentative link between the visions.

As concluded from the earlier steps of the analysis and presented in Figure 6, the bio-ecology vision plays only a marginal role in the media articles. Thus, links to other visions are overall seldom and hold little explanatory power. However, several aspects are worth pointing out. 


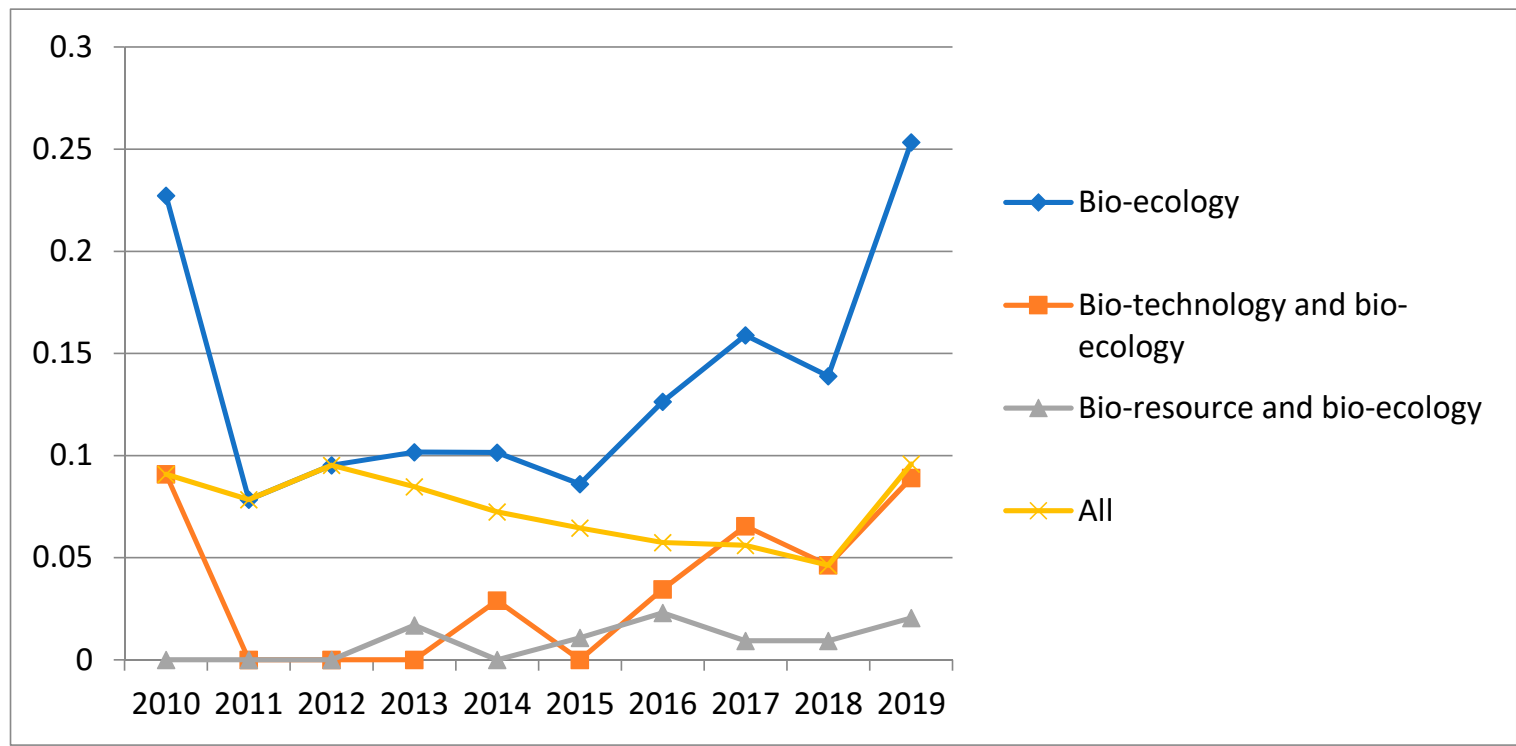

Figure 6. References to bio-ecology vision in relation to the other visions, 2010-2019 (depicted as share of all articles referencing two or more visions).

The bio-resource vision's focus on resource production is thematically close to the ecological issues raised by the bio-ecology vision. Interestingly, links to the bio-technology vision are more common than links to the bio-resource vision. However, this might be a result of the overall dominant position of the bio-technology vision. The connection between the techno-economic perspective of the bio-technology vision and the sustainability perspective of the bio-ecology vision rests on the fundamental assumption that growth and sustainability are not opposed to each other, but are connected. For example, in a long-form article on the Amazon rainforest, scientists argue that researching and documenting biodiversity would generate commercial success, equating ecological and economic objectives [55]. In the few instances that bio-technology and bio-ecology visions connect, it is mostly regarding agricultural issues with the aim of optimizing production and output. It is argued that precision farming simultaneously enables increases in yield and decreases in the burden on resources [51]. Thus, the bio-ecology vision is occasionally referenced in support of the bio-technology vision.

However, the bio-technology vision is also critically reflected against the bio-ecology vision. Individual articles argue that sustainability cannot be exclusively achieved through technologies, but by respecting planetary boundaries and thinking in ecological systems [51]. Thus, the bio-ecology vision offers critical perspectives on the dominant bioeconomy understanding, but its presence in the media discourse is limited.

Moreover, the bio-ecology vision is most commonly found in connection with both of the other visions. This allows for the assumption that, in the rare cases where bioeconomy is understood in terms of the bio-ecology vision, it is in the context of a comprehensive understanding that incorporates several visions of the bioeconomy. Interestingly, however, the bio-ecology vision is also used to criticize the other visions: namely, the commercialization of nature and the utilization of all available biomass (e.g., [51]). Thus, this vision appears primarily in more complex texts that deal with elements of all three bioeconomy visions. This further underlines the limited relevance of the bio-ecology vision in the media articles.

Lastly, we highlight a finding that was not covered by the analytical framework. Few articles mentioned issues of animal health and well-being in the context of agriculture and food production, an aspect that was not explicitly included in any of the three bioeconomy visions (e.g., [36]). This can be explained by the relatively prominent role of agriculture in the German media in general, or interpreted as an extension of the bio-ecology argument to safeguard natural cycles and ecosystem services. 


\section{Discussion of Potential Pathways}

The German public perception of the bioeconomy, as expressed and reinforced in news media discourse, is surprisingly one-sided. The understanding of the bioeconomy as research and development of new technologies and products for biomass utilization clearly dominates. This results in a pathway based on research policy and start-up funding, centering growth and prosperity because sustainability follows as a natural consequence. This result is supported by a large number of research works on bioeconomy perceptions, which also identify a techno-economic perspective as the most dominant vision $[5,9,10,20,56,57]$. Analyzing the epistemic forms of bioeconomy discourse, Mukhtarov et al. find the bioeconomy concept to be primarily used in a prescriptive way that does not question the transformation as such [5] (p. 10). Our analysis supports this finding, as the bio-technology vision is the most optimistic in regards to implementation and outcome. A possible explanation for this, as Birch discusses, is that "[p]art of the (policy) attraction of the bio-economy seems to be its compatibility with existing social institutions and infrastructures, meaning that it would not require significant changes to social life" [20] (p. 10). This also explains the widespread use of the bio-technology vision because it is the easiest to comprehend and implement, especially for incumbent actors from industry and research who are the most visible in media articles. However, this straight-forward pathway towards the bioeconomy also has a significant drawback, as Birch goes on to explain, because a focus on products allows actors to follow their specific, potentially conflicting objectives, preventing a cross-sectoral approach [20] (pp. 10-11), as suggested by the other two visions. In line with the bio-technology vision, the bioeconomy would develop towards a large palette of bio-technologic products and processes in new and alternative, but unconnected, value-chains and few approaches for the stages of biomass production and the demand-side. However, speed and the extent of the transformation would be limited, due to potentially unaddressed societal and ecologic challenges.

The other two visions for the bioeconomy serve only a marginal role. Often, the bio-resource vision supports the prevailing understanding by extending the perspective to related fields such as biomass production and sustainability goals. Even though the sustainability objective and concerns for climate change and resource degradation are commonly referenced, our analysis reveals that the bio-ecology vision constitutes only a minor stream of media discourse. Literature also suggests that the references to sustainability need to be seen critically. In general, the idea that the bioeconomy could simultaneously meet all goals is heavily criticized (e.g., [28]), a criticism that was also found in the media texts. For the EU bioeconomy policy framework, the understanding of sustainability is found to have shifted towards an emphasis on technological solutions and economic efficiency, with few links to environmental and social aspects [58] (pp. 4176-4178). The strong presence of terms related to environmental issues on the one hand, and the low presence of the bio-ecology vision on the other, demonstrate the mainly rhetorical use. This finding is largely reflected in the media articles under investigation here, with public perception leaning towards a techno-economic pathway and only occasional references to social or ecological aspects.

The bio-ecology vision's minor role may be explained by how the bio-technology framing of bioeconomy as inherently sustainable levers out ecological concerns, especially since the debate overall is on a very abstract (national or global) level. In cases in which the bioeconomy is discussed as a specific (local) development, the articles mostly deal with research outcomes, demonstration projects, or new products-further reinforcing the bio-technology vision. Thus, there is no clear alternative pathway.

This relatively clear distinction between two sides of the debate is also identified in other works of research, as indicated in Section 2.1. Both Priefer et al. (2017) and Stern et al. (2018) determine that generally two pathways can be differentiated: the first dominant one being focused on technology and industry, and the second, alternative one, having a socioecological focus, often on a regional scale $[28,30]$. The bias towards the first pathway is strongly supported by our results.

The only notable criticism of bio-technology is provided by the bio-ecology vision's concern about social issues, especially equity, acceptance, and participation. Although texts broadly acknowledge the 
challenges of society partaking in the transformation, the bio-technology vision offers no suggestion for how a bioeconomy can address those challenges.

In light of the slightly growing use of the bio-ecology vision over time, this vision can thus open up the German public discourse to broader interpretations of the bioeconomy. It is important to emphasize that the duality of ecology and economy, as described in conceptual scientific literature, is also explicitly identified in media articles. However, as the analysis revealed, the bio-technology vision can co-opt ecological arguments to offer a superficial legitimation, so it remains to be seen to what extent the discourse will broaden or change. Regarding potential pathways for the German bioeconomy, ecological and social arguments challenge the current, predominantly technical, direction of development, but no comprehensive alternatives are provided. Thus, in the public perception there is no viable alternative pathway, but only the awareness of problematic aspects of the current bioeconomy transformation. The broadening of bioeconomy perceptions likely complicates the implementation of the currently favored pathway towards the bioeconomy, but it also provides room for conceiving of a pathway that is more holistic, but also better adapted to specific and local requirements.

\section{Conclusions and Outlook}

The concept of the bioeconomy provides visions for a more sustainable future based on two elements: First, the regionalized use of biomass instead of fossil fuels, mitigating climate change and driving rural development and employment opportunities. Second, the development of new or improved value-chains and products by using biotechnology, enabling efficiency gains and economic growth. A transformation towards the bioeconomy requires massive technological and economic changes to the way natural resources are produced and utilized. However, research and real-world experiences highlight the need to also account for society and for how diverse interests, values, and interpretations of the concept have to be balanced to implement the bioeconomy. Thus, a better understanding is needed of how society at large perceives the bioeconomy and which potential pathways emerge from these perceptions.

In this article, we analyzed the public perception of the bioeconomy in Germany as reflected in news media articles published between 2010 and 2019. The German government has developed a strategy to foster a bioeconomy, inter alia, in the lignite mining regions affected by structural change $[6,16]$. Therefore, the strategy is deeply embedded in the context of the country's Energiewende, its climate mitigation plans, and concerns about rural development. In order to characterize prevalent bioeconomy perceptions and transformation pathways, we analyzed the media discourse with a mixed-method approach by coding articles for three bioeconomy visions via the data analysis program MAXQDA. The coding scheme was modeled after the bio-technology, bio-resource, and bio-ecology visions developed by Bugge et al. (2016) [18]. Then, the texts were analyzed quantitatively and qualitatively, identifying the main ideas and arguments as well as the relations among them.

Our analysis revealed a clear dominance of the bio-technology vision, which is focused on the development of biotechnological products and processes to the aims of competitiveness and growth. The bio-resource vision, which focuses instead on the production and cascading use of biomass and the impacts on sustainability and rural development, appears only approximately half as often. This vision is often referenced in combination with the biotechnology vision, extending the perspective to the biomass producing stages of the value-chain. However, the bio-resource vision also adds some critical aspects to the debate, such as concerns about biomass availability, climate change, and global food security. The most critical voices were found in the occasional use of the bio-ecology vision, which calls for circular processes including ecosystem services and for social sustainability goals such as equity and participation. Particularly, the notion of societal acceptance and participation is an important addition to the public perception of the bioeconomy because the predominant vision, bio-technology, does not offer a solution strategy for societal challenges. However, this most critical vision represents only a marginal thread of the public debate as reflected in news articles. Our results can serve as an indication of a trend towards a broadening public debate, which requires further, systematic analysis. 
Given the recently emerging interest in the role of society in the bioeconomy and in sustainability transformations in general, this analysis provides an important contribution to identifying public perceptions of the bioeconomy and to which ideas and arguments underlie them. Thus, conclusions can be drawn about which transformation pathways are socially accepted. Research so far has mostly concentrated on the conceptual roots or on a specific set of actors, often experts. Analyzing media articles instead offers insight into broader society, i.e., people who are stakeholders, consumers, and voters, and who are ultimately key in shaping and successfully implementing the bioeconomy. However, this broader approach also provides broader observations about bioeconomy perceptions. Our analysis is focused on analyzing major streams of public debate. Further research should expand on this by also analyzing changes at the level of words instead of at the level of the article, detailing the use of specific arguments within the text or between different types of media. Since our results also showed a general interest in and support for regional bioeconomy approaches in Germany, differences between regions also constitute an interesting research direction.

Author Contributions: Conceptualization, S.D. and S.V.; methodology, S.D. and S.V.; software, S.D.; formal analysis, S.D.; writing — original draft preparation, S.D.; writing-review and editing, S.D. and S.V.; supervision and project administration, S.V. All authors have read and agreed to the published version of the manuscript.

Funding: This research was funded as part of the Transform2Bio project by the Ministry of Culture and Science of the State of North Rhine-Westphalia within the scope of the NRW Strategieprojekt BioSC [grant number 313/323-400-00213].

Acknowledgments: The authors would like to thank Maria Belka for her support in compiling the media articles via the lexisnexis database.

Conflicts of Interest: The authors declare no conflict of interest. The funders had no role in the design of the study; in the collection, analyses, or interpretation of data; in the writing of the manuscript, or in the decision to publish the results.

\section{Appendix A}

Table A1. Search terms for analyzing frequency of key words.

\begin{tabular}{cccc}
\hline Word Group & Definition of Bioeconomy & $\begin{array}{c}\text { Environmental } \\
\text { Challenges }\end{array}$ & Fields of Action \\
\hline Search terms & $\begin{array}{c}\text { biotechnology } \\
\text { biomass } \\
\text { resource and raw materials } \\
\text { product } \\
\text { energy } \\
\text { circularity }\end{array}$ & $\begin{array}{c}\text { climate change } \\
\text { environment } \\
\text { sustainability }\end{array}$ & $\begin{array}{c}\text { agriculture and forestry } \\
\text { science and research } \\
\text { industry and company } \\
\text { society and citizen } \\
\text { politics }\end{array}$ \\
\hline
\end{tabular}

Table A2. German search terms for analyzing frequency of key words.

\begin{tabular}{|c|c|c|c|}
\hline Word Group & Definition of Bioeconomy & $\begin{array}{c}\text { Environmental } \\
\text { Challenges }\end{array}$ & Fields of Action \\
\hline Search terms & $\begin{array}{c}\text { Biotechnologi }{ }^{*} \\
\text { Biomasse } \\
\text { Ressource */Rohstoff* } \\
\text { Produkt * } \\
\text { Energ* } \\
\text { Kreislauf */Zirkulär } \\
\text { */Circular } \\
\text { Ernährung */Lebensmittel * }\end{array}$ & $\begin{array}{c}\text { Klimawandel * } \\
\text { Umwelt * } \\
\text { Nachhaltig * }\end{array}$ & $\begin{array}{c}\text { Landwirtschaft } \\
\text { */Forstwirtschaft* } \\
\text { /Agrarwirtschaft * } \\
\text { Forschung */Wissenschaft * } \\
\text { Industrie */Unternehmen * } \\
\text { Gesellschaft */Bürger * } \\
\text { Politi * }\end{array}$ \\
\hline
\end{tabular}

${ }^{*}$ indicates that the term is incomplete, allowing for the German language's particularity of compound words to be accounted for in word searches. 


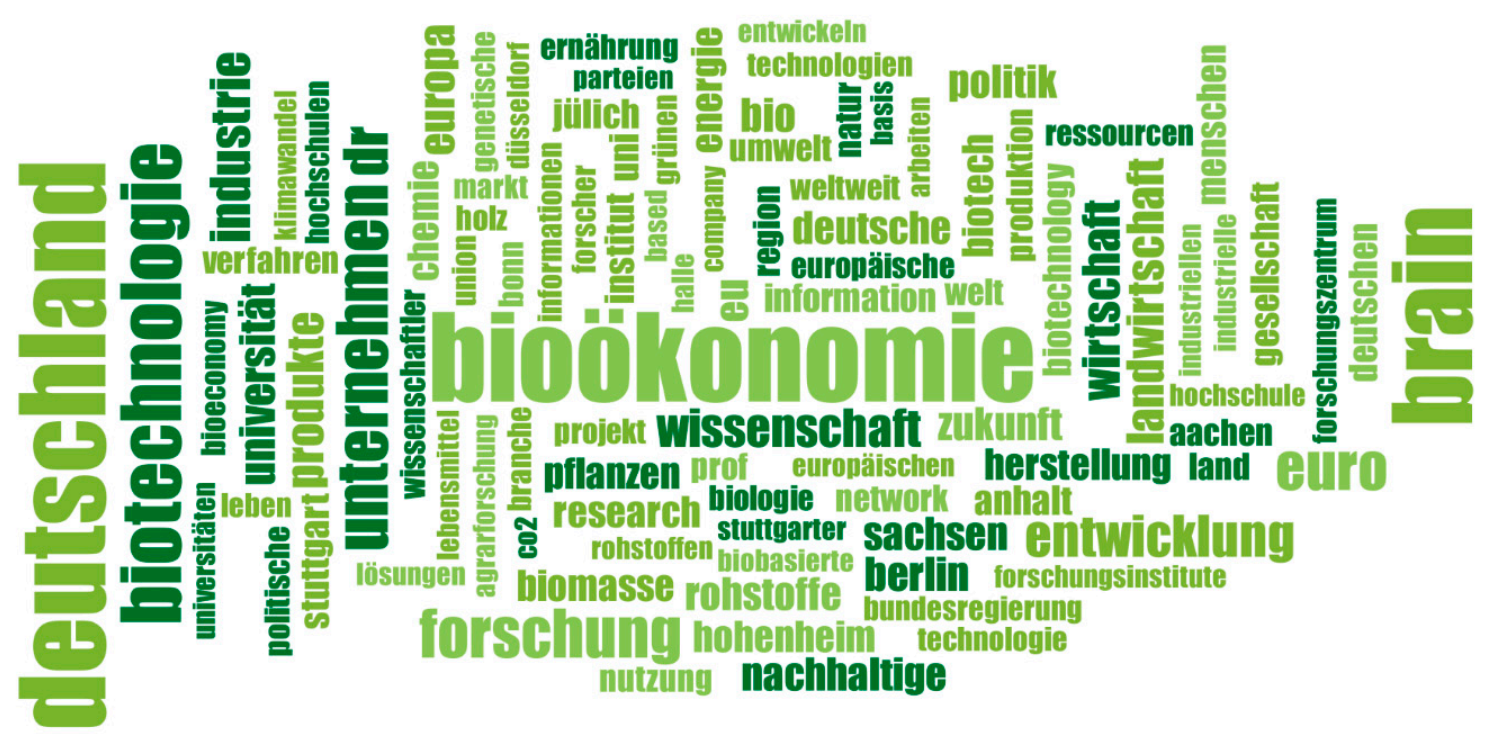

Figure A1. Word cloud for news media texts dealing with the bioeconomy (in German).

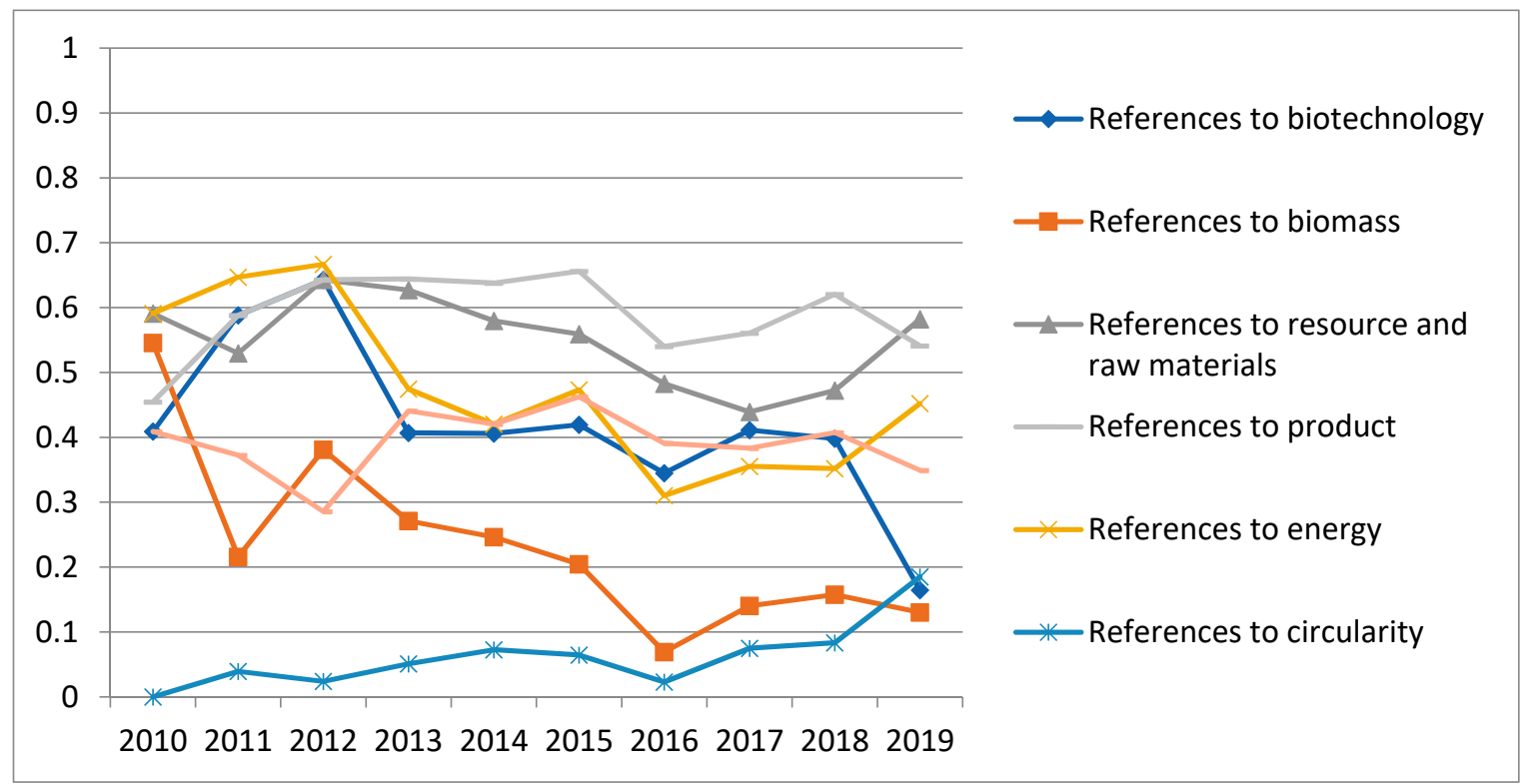

Figure A2. Results of word search for key terms used for defining the bioeconomy.

\section{References}

1. Federal Ministry of Education and Research. En Route to the Knowledge-Based Bio-Economy; German Presidency of the Council of the European Union: Bonn, Germany, 2007.

2. Organisation for Economic Co-Operation and Development. The Bioeconomy to 2030: Designing a Policy Agenda; OECD: Paris, France, 2009; ISBN 9264038531.

3. Staffas, L.; Gustavsson, M.; McCormick, K. Strategies and policies for the bioeconomy and bio-based economy: An analysis of official national approaches. Sustainability 2013, 5, 2751-2769. [CrossRef]

4. Priefer, C.; Meyer, R. One Concept, Many Opinions: How Scientists in Germany Think about the Concept of Bioeconomy. Sustainability 2019, 11, 4253. [CrossRef]

5. Mukhtarov, F.; Gerlak, A.; Pierce, R. Away from fossil-fuels and toward a bioeconomy: Knowledge versatility for public policy? Environ. Plan. C Politics Space 2017, 35, 1010-1028. [CrossRef]

6. Federal Government of Germany. Nationale Bioökonomiestrategie; Federal Government of Germany: Berlin, Germany, 2020.

7. Kiresiewa, Z.; Hasenheit, M.; Wolff, F.; Möller, M.; Gesang, B.; Schröder, P. Bioökonomiekonzepte und Diskursanalyse; No. 78; Umweltbundesamt: Dessau-Roßlau, Germany, 2019. 
8. Vainio, A.; Ovaska, U.; Varho, V. Not so sustainable? Images of bioeconomy by future environmental professionals and citizens. J. Clean. Prod. 2019, 210, 1396-1405. [CrossRef]

9. Hausknost, D.; Schriefl, E.; Lauk, C.; Kalt, G. A Transition to Which Bioeconomy? An Exploration of Diverging Techno-Political Choices. Sustainability 2017, 9, 669. [CrossRef]

10. Peltomaa, J. Drumming the Barrels of Hope? Bioeconomy Narratives in the Media. Sustainability 2018, 10, 4278. [CrossRef]

11. Kleinschmit, D.; Arts, B.; Giurca, A.; Mustalahti, I.; Sergent, A.; Puelzl, H. Environmental concerns in political bioeconomy discourses. Int. For. Rev. 2017, 19, 41-55. [CrossRef]

12. Federal Ministry of Education and Research. Nationale Forschungsstrategie BioÖkonomie 2030: Unser Weg zu einer Bio-Basierten Wirtschaft; Bonn: Berlin, Germany, 2010.

13. Federal Ministry of Food and Agriculture. Nationale Politikstrategie Bioökonomie: Nachwachsende Rohstoffe und biotechnologische Verfahren als Basis für Ernährung, Industrie und Energie; Federal Ministry of Food and Agriculture: Bonn, Germany, 2014.

14. Federal Ministry for Economic Affairs and Energy. Energiewende. Available online: https://www.bmwi.de/ Redaktion/DE/Dossier/energiewende.html (accessed on 30 August 2020).

15. Reusswig, F.; Braun, F.; Heger, I.; Ludewig, T.; Eichenauer, E.; Lass, W. Against the wind: Local opposition to the German Energiewende. Util. Policy 2016, 41, 214-227. [CrossRef]

16. Commission WSB. Abschlussbericht; Federal Ministry for Economic Affairs and Energy: Berlin, Germany, 2019.

17. Federal Ministry of Education and Research. Wissenschaftsjahr 2020/2021 Bioökonomie. Available online: https://www.wissenschaftsjahr.de/2020-21/ (accessed on 30 August 2020).

18. Bugge, M.M.; Hansen, T.; Klitkou, A. What Is the Bioeconomy? A Review of the Literature. Sustainability 2016, 8, 691. [CrossRef]

19. Berg, S.; Cloutier, L.M.; Bröring, S. Collective stakeholder representations and perceptions of drivers of novel biomass-based value chains. J. Clean. Prod. 2018, 200, 231-241. [CrossRef]

20. Birch, K. Emergent imaginaries and fragmented policy frameworks in the Canadian bio-economy. Sustainability 2016, 8, 1007. [CrossRef]

21. Leipold, S.; Feindt, P.H.; Winkel, G.; Keller, R. Discourse analysis of environmental policy revisited: Traditions, trends, perspectives. J. Environ. Policy Plan. 2019, 21, 445-463. [CrossRef]

22. Hajer, M.; Versteeg, W. A decade of discourse analysis of environmental politics: Achievements, challenges, perspectives. J. Environ. Policy Plan. 2005, 7, 175-184. [CrossRef]

23. Paltridge, B. Discourse Analysis: An Introduction; Bloomsbury Publishing: London, UK, 2012.

24. Ranacher, L.; Ludvig, A.; Schwarzbauer, P. Depicting the peril and not the potential of forests for a biobased economy? A qualitative content analysis on online news media coverage in German language articles. For. Policy Econ. 2019, 106. [CrossRef]

25. Puttkammer, J.; Grethe, H. The Public Debate on Biofuels in Germany: Who Drives the Discourse? Ger. J. Agric. Econ. 2015, 64, 263-273.

26. Giurca, A. Unpacking the network discourse: Actors and storylines in Germany's wood-based bioeconomy. For. Policy Econ. 2020, 110, 1-9. [CrossRef]

27. Cobb, C.W.; Cobb, J.B. The Green National Product: A Proposed Index of Sustainable Economic Welfare; University Press of America: Lanham, MA, USA; London, UK, 1994.

28. Priefer, C.; Joerissen, J.; Froer, O. Pathways to Shape the Bioeconomy. Resources 2017, 6, 10. [CrossRef]

29. Georgescu-Roegen, N. The Entropy Law and the Economic Process; Harvard University Press: Lincoln, NE, USA, 1971.

30. Stern, T.; Ploll, U.; Spies, R.; Schwarzbauer, P.; Hesser, F.; Ranacher, L. Understanding Perceptions of the Bioeconomy in Austria-An Explorative Case Study. Sustainability 2018, 10, 4142. [CrossRef]

31. Rädiker, S.; Kuckartz, U. Analyse qualitativer Daten mit MAXQDA; Springer: Wiesbaden, Germany, 2019.

32. Maxwell, J.A.; Chmiel, M. Notes toward a theory of qualitative data analysis. In The SAGE Handbook of Qualitative Data Analysis; SAGE Publications: Thousand Oaks, CA, USA, 2014; pp. 21-34.

33. Gibbs, G.R. Using software in qualitative analysis. In The SAGE Handbook of Qualitative Data Analysis; SAGE Publications: Thousand Oaks, CA, USA, 2014; pp. 277-294.

34. Grefe, C. Forschungsleiter Mikrobe. Die ZEIT, 19 November 2015.

35. Budzinski, A. Rasante Fahrt ins Grüne. Chemie Plus/Chemische Rundschau, 7 March 2011. 
36. Schneider, R.E. Biotechnologie unter volkswirtschaftlichen Aspekten betrachtet. Labo-Magazin Labortechnik 2011, 5, 48 .

37. Grefe, C.; Sentker, A. Und bald ist einfach alles bio: Nahrung, Energie, Rohstoffe soll der Acker liefern-So sehen Experten die Zukunft der Landwirtschaft. Die ZEIT, 9 September 2010.

38. Iost, S.; Labonte, N.; Banse, M.; Geng, N.; Jochem, D.; Schweinle, J.; Weber, S.; Weimar, H. German Bioeconomy: Economic Importance and Concept of Measurement. Ger. J. Agric. Econ. 2019, 68, 275-288.

39. Bronsema, V. Ein weißer Ritter? Die Biotechnologie bahnt in ihrer industriellen Ausprägung der Chemie den Weg. CITplus, 6 September 2011.

40. Ahrens, R. Wo Ingenieure und Biologen Hand in Hand arbeiten. VDI Nachrichten, 12 June 2015.

41. NN. DGAP-News: BRAIN AG plant Börsengang. dpa-AFX ProFeed, 5 January 2016.

42. NN. Auf der Suche nach dem heiligen Gral; Von Glycerin bis Bernsteinsäure-welches ist die vielversprechendste biobasierte Chemikalie? CHEManager, 3 May 2018.

43. NN. Wissenschaft hinter dem Zaun hilft nicht: Professor Ulrich Schurr und die Jülicher Pflanzenforscher wollen mit Landwirten und Züchtern an der Zukunft der Region arbeiten. Aachener Nachrichten, 15 August 2019.

44. Gross, J. Natürlich gut: Der Einsatz von nachwachsenden Rohstoffen und darauf basierenden Technologien etabliert sich zunehmend in einer Vielzahl von Branchen. Auch für Anleger ist der Trend attraktiv. Euro am Sonntag, 4 April 2015.

45. Jopp, K. Was kommt nach dem Erdöl?: Forscher entwickeln Alternativen für den wichtigsten Rohstoff der chemischen Industrie. Eine Schlüsselrolle spielen biologische Verfahren. Die Welt, 23 December 2013.

46. Kircher, M.; Bayer, T. Rohstoffwandel braucht Rohstoffeffizienz: Das Portfolio biobasierter Rohstoffe muss erweitert werden, um einen Wandel zu ermöglichen. CHEManager, 3 May 2018.

47. Konle, S. Rohstoffquellen der Zukunft: Moderne Kreislaufwirtschaft = Nachhaltige Kreislaufwirtschaft. Labo-Magazin für Labortechnik 2019, 4, 30.

48. NN. Elektrifizierung der Bioökonomie: Chemikalien und Proteine aus $\mathrm{CO}_{2}$ und erneuerbarem Strom. CHEManager, 9 October 2019.

49. Krsteski, J. Aufbruch in eine neue Ära: Unsere natürlichen Ressourcen neigen sich dem Ende zu. Kann die Forschung nachhaltige Lösungen finden, indem sie sich biologische Systeme in der Natur zum Vorbild nimmt? Kölnische Rundschau, 21 September 2019.

50. Mönch, A. Lebensmittelabfälle effektiver verwerten: Reichlich Potenzial in der EU vorhanden-Nachhaltige Landwirtschaft wird wichtiger. Agrarzeitung Ernährungsdienst, 17 February 2012.

51. Grefe, C.; Sentker, A. Streit um die neuen Bauernregeln: Die Bundesregierung plant den Ausbau der Agrarforschung. Aber mit welchen Zielen? Zwei Kontrahenten debattieren über Knappheit, Gentechnik und langfristiges Denken. Die ZEIT, 8 July 2010.

52. Miethke, N. Hat die Lausitz noch eine Chance? Sächsische Zeitung Stammausgabe Dresden, 23 November 2018.

53. Tenta, S. Rheinisches Revier: Fahrplan für den Strukturwandel. WebNews-German (tagesschau.de), 24 October 2019.

54. Schumann, J. Alles wird Bio: In Sachsen-Anhalt forschen Wissenschaftler für eine Zukunft ohne Erdöl. Ihre Ideen zur Nutzung nachwachsender Rohstoffe stehen im Einklang mit Zielen der EU. Mitteldeutsche Zeitung, 14 June 2017.

55. Fischermann, T. Ein Dschungel wird abgewickelt: Brasilien fackelt seinen Regenwald ab, dabei gab es mal einen anderen Plan: Mit dem natürlichen Reichtum Amazoniens wollte das Land Milliarden erwirtschaften, ein neues Institut sollte die Grundlage legen. Es kam anders. Die ZEIT, 29 August 2019.

56. McCormick, K.; Kautto, N. The Bioeconomy in Europe: An Overview. Sustainability 2013, 5, $2589-2608$. [CrossRef]

57. Hempel, C.; Will, S.; Zander, K. Societal Perspectives on a Bio-economy in Germany: An Explorative Study Using Q Methodology. Int. J. Food Syst. Dyn. 2019, 10, 21-37. [CrossRef]

58. Ramcilovic-Suominen, S.; Puelzl, H. Sustainable development-A 'selling point' of the emerging EU bioeconomy policy framework? J. Clean. Prod. 2018, 172, 4170-4180. [CrossRef]

(C) 2020 by the authors. Licensee MDPI, Basel, Switzerland. This article is an open access article distributed under the terms and conditions of the Creative Commons Attribution (CC BY) license (http://creativecommons.org/licenses/by/4.0/). 